\title{
Does immigration play a role in the risk of gastric cancer by site and by histological type? A study of first-generation immigrants in Sweden
}

\author{
Seyed Mohsen Mousavi · Jan Sundquist • \\ Kari Hemminki
}

Received: 9 December 2010/ Accepted: 13 February 2011/Published online: 23 March 2011

(c) The International Gastric Cancer Association and The Japanese Gastric Cancer Association 2011

\begin{abstract}
The observed increased risks of gastric cancer among first-generation immigrants compared to those in Swedes suggest the role of childhood environmental exposure in the risk of this disease.
\end{abstract}

Keywords Adenocarcinoma - Cardia - Gastric cancer . Immigrants $\cdot$ Risk $\cdot$ Sweden

\section{Introduction}

The distribution of gastric cancer is characterized by wide geographical variations [1]. The highest rates (about 20/100,000) have been reported from Japan, China, and some Latin American countries. The lowest rates, of less than 6/100,000, are reported from North America, Northern and Western Europe, most African countries, the Indian

S. M. Mousavi $(\bowtie) \cdot$ K. Hemminki

Division of Molecular Genetic Epidemiology, German Cancer Research Center (DKFZ), Im Neuenheimer Feld 580, 69120 Heidelberg, Germany

e-mail:m.mousavi@dkfz.de

S. M. Mousavi

Cancer Research Center of Cancer Institute,

Tehran University of Medical Sciences, Tehran, Iran

J. Sundquist $\cdot$ K. Hemminki

Centers for Primary Care Research, Lund University,

Malmö, Sweden

J. Sundquist

Stanford Prevention Research Center, Stanford University

School of Medicine, Stanford, CA, USA subcontinent, and Australia [2]. The gastric cancer rate in men $(5.7 / 100,000)$ is about two times higher than that in women $(3.1 / 100,000)$ in Sweden [2].

Worldwide, a decreased rate of gastric cancer has been reported for several decades. However, the incidence rate of cancer of the cardia, the proximal part of the stomach, has been showing an increased rate in some developed countries [1]. Similarly, the incidence of esophageal adenocarcinoma has been increasing in those countries since the 1970s [3], which suggests the presence of the same risk factors, such as obesity or gastroesophageal reflux [4]. Helicobacter pylori infection is a known risk factor for non-cardia gastric cancer. A diet poor in fresh fruits and vegetables and a highsalt intake are other associated factors. However, studies have also suggested that genetic susceptibility, familial aggregation, and blood group (A) have an influence on gastric cancer risk [1].

Previous studies have not shown uniform patterns of gastric cancer risk among immigrants. For example, a sharply decreased risk of gastric cancer was reported among Korean-Americans compared with their native counterparts, and even compared with the white United States population [5]. Such a difference was also reported among Japanese immigrants in Brazil [6]. In contrast, Chinese male immigrants to the United States were reported to have a rate similar to that of white Americans, whereas the rate in female Chinese immigrants was twice that of white Americans [7].

To our knowledge no study has explored whether the gastric cancer risk in immigrants varies by different site and histology. In the present report, we studied the risk of gastric cancer by site, histological type, and length of stay in first-generation immigrants to Sweden in order to search for etiological clues. 


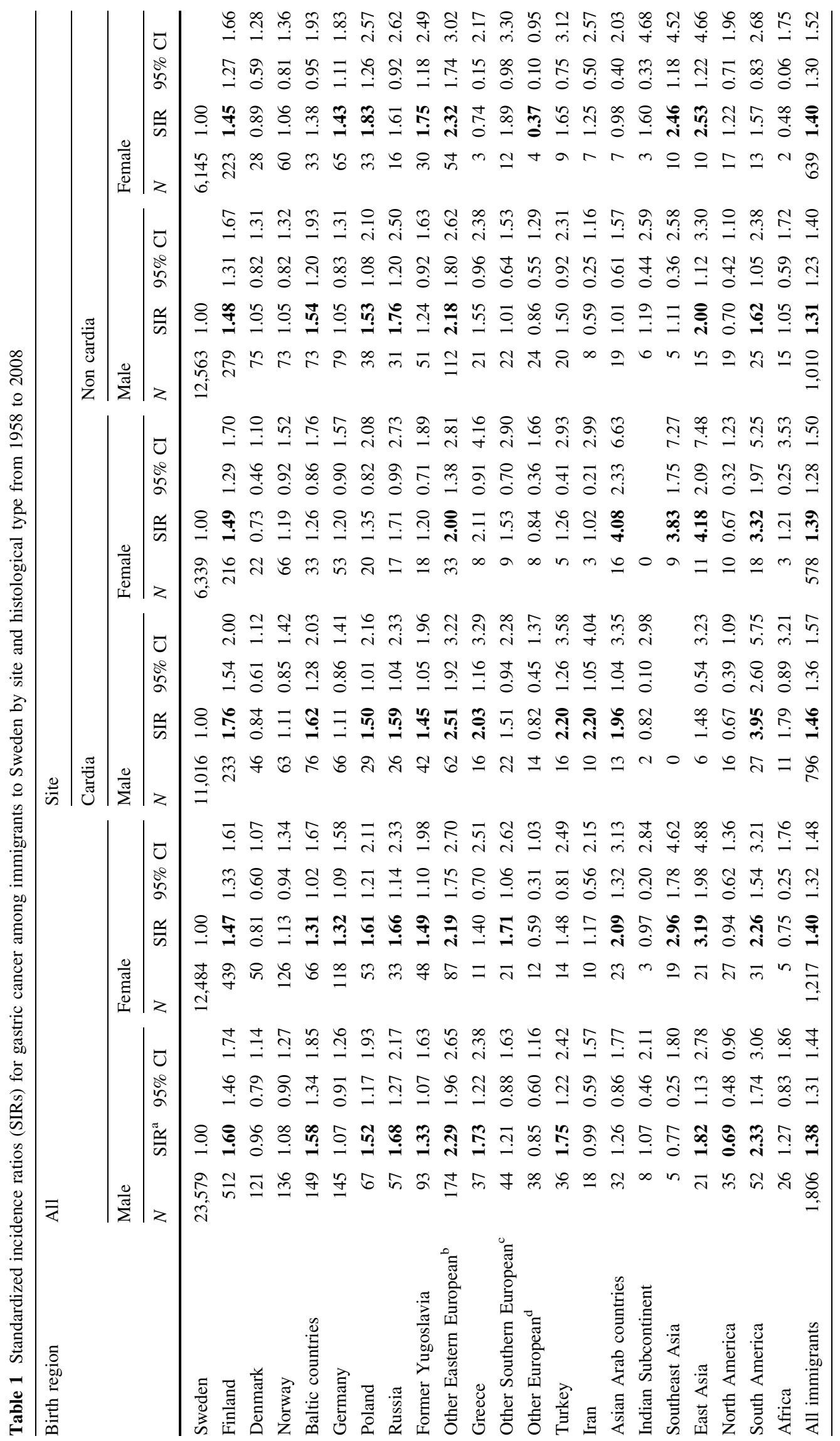




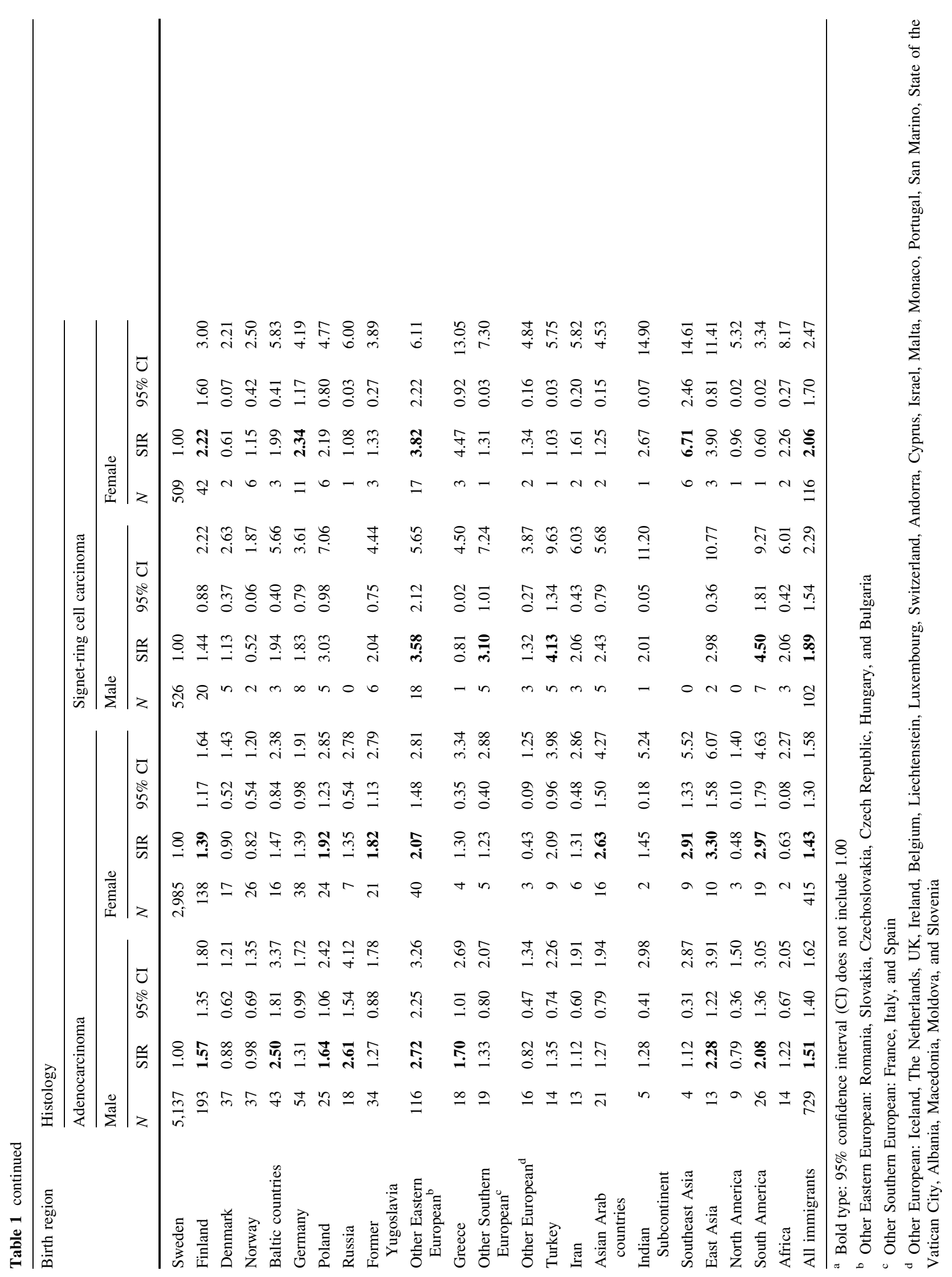




\section{Subjects, materials, and methods}

We used the 2010 update of the Swedish Family-Cancer Database (FCD) for the present study [8]. Data on cancers in the FCD have a 4-digit diagnostic code according to the 7th revision of the ICD (http://www.wolfbane.com/icd): cardia $(\mathrm{ICD}=1510)$. From 1993 onwards, the Systematized Nomenclature of Medicine (SNOMED) has been used: adenocarcinoma $($ SNOMED $=8140$ ) and signet-ring cell carcinoma (8490) [9]. All gastric cancers (100\%) reported to the Cancer Registry are histologically and anatomically verified. First-generation immigrants were defined as those born outside Sweden without identified parents in the Database. The start of follow-up was defined as the birth year, the date of immigration, or January 1, 1958, whichever came latest. For the histology-specific standardized incidence ratio (SIR), the start of follow-up was January 1, 1993. If the date of immigration was missing (about 134,000 immigrants), follow-up was started on the first year in which the immigrant was present in a census. The end of follow-up was defined as the date of cancer diagnosis, death, or emigration, or the end of the last year of presence in the census, or the closing date of our study, December 31, 2008, whichever came earliest.

Standardized incidence ratios (SIRs) were calculated as the ratio of the observed to expected numbers of cases. The expected numbers were calculated from 5-year age groups, sex and time periods (10-year bands from 1958 to 2008) in native Swedes as the reference population. Additionally, the effect of residential time was tested for two groups: time since immigration $<20$ years and $\geq 20$ years. Confidence intervals $(95 \% \mathrm{CI})$ were calculated assuming a Poisson distribution. SAS software ver.9.2 was used for the data analysis (SAS Institute, Cary, NC, USA).

\section{Results}

The FCD included 23,579 male and 12,484 female cases of gastric cancer in native Swedes, and 1,806 and 1,217 cases in immigrants, respectively (Table 1). As compared to the native Swedes, the risk of gastric cancer was increased in all immigrants $($ SIR: men $=1.38$, women $=1.40)$, except for North American men (0.69). The highest risk of cardia gastric cancer was seen among South American men (3.95) and some Asian (3.83-4.18) and South American (3.32) women. The highest risk of non-cardia gastric cancer was seen among "other East Europeans" (see Table 1 for definitions of the regional categories) $($ men $=2.18$, women $=2.32$ ), and Southeast Asian and East Asian women (2.46-2.53). Only "other European" women had a decreased risk (0.37). The highest risk of adenocarcinoma was seen among some Eastern European men (2.61-2.72) and some Asian (2.63-3.30) and South American (2.97) women. However, Finnish, German, and Southeast Asian women; and "other Eastern European”, "other Southern European", Turkish, and South American men had the highest risk of signet-ring cell carcinoma (2.22-6.71).

No trend was observed for the risks in immigrants according to the length of stay. For example, increased risks were observed for immigrant men $(N=687$, $\mathrm{SIR}=1.44,95 \% \mathrm{CI}=1.34-1.56)$ and women $(N=470$, $\mathrm{SIR}=1.63,95 \% \mathrm{CI}=1.49-1.79)$ who had resided in Sweden for less than 20 years. However, the risks remained high among immigrant men $(N=1,119$, $\mathrm{SIR}=1.34,95 \% \mathrm{CI}=1.26-1.42)$ and women $(N=747$, $\mathrm{SIR}=1.28,95 \% \mathrm{CI}=1.19-1.38)$ who had resided in Sweden for more than 20 years (data not shown).

\section{Discussion}

Increased risks of gastric cancer among immigrants were observed in both anatomical sites noted in the present study: cardia and non-cardia. Also, these increased risks were mostly attributable to the increased risks of adenocarcinoma, which had a higher frequency than other histological types. Our findings reflect the incidence rates in the immigrants' countries of origin [9]. For example, Finns showed an increased risk of gastric cancer, which was higher in Finland compared with Sweden [10-12].

Risk factors for gastric cancer, such as diet and Helicobacter pylori infection, may have been retained upon migration [13, 14]. We found that the observed increased risks among immigrants were independent of the length of stay. Our results, in line with the GLOBOCAN-2008 report [2] and the geographical spread of Helicobacter pylori [15], may show a major role for childhood environmental exposure in the etiology of gastric cancer.

The number of gastric cancer cases among secondgeneration immigrants was too small $(N=123)$ for further consideration. However, the study of second-generation immigrants may show the role of gene-environmental interaction in the etiology of this cancer.

Acknowledgments This study was supported by the German Cancer Research Center (DKFZ) guest scientist program, Deutsche Krebshilfe, the Swedish Cancer Society, and the Swedish Council for Working Life and Social Research.

\section{References}

1. Boyle P, Levin B. World Cancer Report 2008. Lyon: IARC; 2008.

2. GLOBOCAN 2008, Cancer Incidence and Mortality Worldwide: IARC Cancer Base No. 10 (Internet). (database on the Internet). International Agency for Research on Cancer. 2010 (cited 2010). Available from: http://globocan.iarc.fr. 
3. Mousavi SM, Brant A, Sundquist J, Hemminki K. Esophageal cancer risk among immigrants in Sweden. Eur J Cancer Prev. 2011;20(2):71-6.

4. Falk GW. Risk factors for esophageal cancer development. Surg Oncol Clin N Am. 2009;18(3):469-85.

5. Lee J, Demissie K, Lu SE, Rhoads GG. Cancer incidence among Korean-American immigrants in the United States and native Koreans in South Korea. Cancer Control. 2007;14(1):78-85.

6. Tsugane S, de Souza JM, Costa ML Jr, Mirra AP, Gotlieb SL, Laurenti R, et al. Cancer incidence rates among Japanese immigrants in the city of Sao Paulo, Brazil, 1969-78. Cancer Causes Control. 1990;1(2):189-93.

7. Kamineni A, Williams MA, Schwartz SM, Cook LS, Weiss NS. The incidence of gastric carcinoma in Asian migrants to the United States and their descendants. Cancer Causes Control. 1999;10(1):77-83.

8. Hemminki K, Ji J, Brandt A, Mousavi SM, Sundquist J. The Swedish family-cancer database 2009: Prospects for histologyspecific and immigrant studies. Int J Cancer. 2009.

9. Hemminki K, Li XJ, Czene K. Cancer risks in first-generation immigrants to Sweden. Int J Cancer. 2002;99(2):218-28.
10. Hemminki K, Li X. Cancer risks in Nordic immigrants and their offspring in Sweden. Eur J Cancer. 2002;38(18):2428-34.

11. Ferlay J, Autier P, Boniol M, Heanue M, Colombet M, Boyle P. Estimates of the cancer incidence and mortality in Europe in 2006. Ann Oncol. 2007;18(3):581-92.

12. Engholm G, Ferlay J, Christensen N, Bray F, Gjerstorff ML, Klint $\AA$, et al. NORDCAN: Cancer Incidence, Mortality, Prevalence and Prediction in the Nordic Countries, Version 3.6. Association of the Nordic Cancer Registries. Danish Cancer Society (http:// www.ancr.nu). (cited Jan. 2010); Available from: http://wwwdep.iarc.fr/NORDCAN/english/frame.asp.

13. Moradi T, Delfino RJ, Bergstrom SR, Yu ES, Adami HO, Yuen J. Cancer risk among Scandinavian immigrants in the US and Scandinavian residents compared with US whites, 1973-89. Eur J Cancer Prev. 1998;7(2):117-25.

14. Nilsson B, Gustavson-Kadaka E, Rotstein S, Hakulinen T, Rahu M, Aareleid T. Cancer incidence in Estonian migrants to Sweden. Int J Cancer. 1993;55(2):190-5.

15. Suerbaum S, Michetti P. Helicobacter pylori infection. N Engl J Med. 2002;347(15):1175-86. 